\title{
ENSINAR, UMA PROFISSÃO FEMININA? EXPLANANDO ASPECTOS CONCEITUAIS E HISTÓRICOS ${ }^{1}$ (FINAL DO SÉCULO XIX AOS DIAS ATUAIS)
}

\author{
TEACH, A FEMALE PROFESSION? \\ EXPLAINING CONCEPTUAL AND HISTORICAL ASPECTS \\ (THE LATE NINETEENTH CENTURY TO TODAY)
}

\author{
Maria Renata Azevedo²
}

Recebido em: 28/03/2011

Aprovado em: 06/02/2012

\section{RESUMO}

Investigar, contextualizar, explanar e discutir as questões de gênero na docência são os principais objetivos deste trabalho, que conta com um levantamento bibliográfico referente ao tema e com uma apreciação sobre os aspectos conceituais e históricos da profissão docente.

Palavras-chave: Gênero; Docência; Educação.

\section{Introdução}

Ao percorrermos estatísticas trazidas pelos autores aqui trabalhados, ou mesmo verificando o cotidiano das escolas, vamos encontrar um número muito maior de mulheres do que de homens na condução das salas de aula. Tais dados tornam-se ainda mais visíveis quando se tratam de turmas de anos iniciais ou de educação infantil.

Quando temos contato com pesquisas de cunho histórico, de autores/ as como ALMEIDA (1998), WERLE (2005) e LOURO (1995), por exemplo, ficamos sabendo que o magistério, assim como a maioria das outras profissões, era, em sua essência, masculi-

\begin{abstract}
Investigate, contextualize, explain and discuss gender issues in teaching are the main objectives of this article, which contains a bibliography compendium of the theme and an assessment of the aspects concepts and historics of the teaching profession.

Keywords: Gender; Teaching; Education.
\end{abstract}

no. Porém, por vários motivos (salário baixo, trabalho cansativo e "feminino", etc.), sempre houve falta de professores, o que oportunizou a entrada de meninas nesse mercado de trabalho.

Segundo Werle (2005), referindo-se ao período histórico do final do século XIX, muitos foram os argumentos para que se permitisse a entrada de moças no magistério. As primeiras professoras, por exemplo, eram aquelas meninas órfãs que, de certo modo, tinham um "débito" com o Estado, afinal, eram sustentadas e criadas pelo mesmo, e, ao atingir a idade adulta, deveriam trabalhar para retribuir o "carinhoso atendimento". Deste modo, fica clara aqui a idéia de que o governo estava apenas

\footnotetext{
${ }^{1}$ Este artigo é um recorte do Trabalho de Conclusão de Curso da autora, intitulado Professores(as) de História e Histórias de Professores (as), aprovado com Distinção em 2008/2 pela Universidade do Vale do Rio dos Sinos-UNISINOS, no qual se discutem gênero, educação, profissão docente, ensino de história e de história oral.

${ }^{2}$ Graduada em História Licenciatura Pelna pela Universidade do Vale do Rio dos Sinos - UNISINOS. E-mail: liloazevedo@yahoo.com,br. 
"aproveitando uma mão de obra barata”, já que essa era a única oportunidade de trabalho oferecida para essas órfãs. Conforme Werle (2005), marcado pela gratidão e dívida para com a sociedade, era um magistério devedor, que retribuía os favores recebidos ministrando ensino em escolas públicas.

Tentando encobrir o fato de que talvez a maioria dessas meninas não tivesse nenhuma identificação pessoal com a profissão, começamos a difundir a idéia de que "ensinar é um trabalho feminino", pois reproduz o trabalho doméstico (que também era visto como exclusivamente feminino). Afinal, a escola era a responsável por ensinar, além das disciplinas, também as boas maneiras, exatamente como ensinavam as mães, ou seja, ensinar a ir ao banheiro, a comer corretamente, a orar, a não desobedecer, etc. Logo, ser professora é um trabalho para mulheres. Precisamos levar em conta também que, justamente por não possuírem famílias, as professoras órfãs tinham tempo disponível para atender os alunos e os problemas da escola, como se "ensinar fosse uma espécie de sacerdócio", exigindo tempo e dedicação integrais. Podemos afirmar que na época diziam, inclusive, que o prazer de ensinar era tanto, que essas mulheres abdicavam de seus desejos pessoais, especialmente os "amorosos", chegando a "esquecer de casar e constituir família", pois, no lugar de filhos próprios, elas tinham de se ocupar de inúmeros "filhos postiços" que as escolas the ofertavam.

Há mais semelhanças nas duas naturezas infantil e feminina. A inocência, a curiosidade, a bondade, o sentimento, as lágrimas, os sorrisos, e até a voz, tudo se harmoniza na mulher e no menino. Todas as leis do coração levam o menino para a mulher e não para o homem; e que admira isto, se foi nas entranhas femininas que ele recebeu já uma antevida (VILLANOVA, 1877).

\section{Ensinar, uma profissão feminina?}

Embora hoje as mulheres, estejam cada vez mais ocupadas com a profissão (seja ela qual for), com os estudos, com a família, contando com a ajuda de um companheiro (ou não) para realização de serviços domésticos, entre outros, não é difícil acompanharmos, nos filmes e nas novelas, aquela imagem da "professorinha" sempre linda e sempre bem arrumada, além de querida, inteligente, educada, meiga e, claro, sempre solteira ou então a procura de algum "amor impossível". Por mais que lutemos, a imagem da mulher/professora está impregnada na mentalidade da sociedade, tanto que, por algum outro motivo relacionado a este, o número de professoras de séries iniciais é muito maior que o número de professores. Mesmo que muitas meninas tenham se tornado professoras por vontade de terceiros, também existiram aquelas que optaram por essa profissão, visando um mínimo de "independência". Mesmo estando sob a guarda dos pais, ou então dos maridos, ser professora era uma oportunidade de conhecer outras mulheres, outro universo que não o "do lar". A questão central é que, inclusive nas escolas onde se preparavam para serem professoras, as mulheres eram instruídas por homens, bem como nos locais onde exerceriam sua futura profissão. Ainda que as escolas fossem aos poucos "invadidas" por mulheres, estas eram "somente" professoras coordenadas por um diretor.

Disciplinada pelos homens, a educação das mulheres continuou um prolongamento da educação familiar e, enquanto estudavam, as jovens aguardavam o casamento - o que realmente importava em suas vidas. Deixaram de ser as procriadoras incultas para tornarem-se as futuras esposas educadas, conhecedoras das necessidades do marido e dos filhos, alicerces da moral e dos costumes, fiéis e guardiãs do lar cristão e patriótico (ALMEIDA, 1998, p. 31). 
Com o passar dos anos, esse pensamento de "independência" foi tomando corpo, e fazendo com que algumas mulheres percebessem que não havia necessidade de casarem-se, afinal, para elas, a idéia de "não ser feliz, mas ter um marido", não fazia mais sentido.

O magistério primário representou o ponto de partida e o que foi possível no momento histórico vivido. $\mathrm{E}$ foi paixão, no sentido do desejo, do esforço, de aproveitar a oportunidade e conseguir uma inserção no espaço público e no mundo do trabalho. Após isso, alguns direitos posteriores podem ser associados à conquista do magistério pelas mulheres, como a educação feminina, a co-educação, uma certa independência econômica e pessoal, o voto, a licença maternidade e outros (ALMEIDA, 1998, p. 75).

O que talvez não tenha mudado ao longo dos anos foi justamente o sentimento das mulheres em relação às outras mulheres, ou seja, quando todas eram "somente" professoras, coordenadas por um homem, tudo andava conforme o esperado, o "sabido", posto que a surpresa e, muitas vezes, o desgosto ocorriam quando uma das colegas deixava o "pobre" cargo para tornar-se diretora, por exemplo. Esse fato pode ser percebido, infelizmente, em diversas áreas, mas, na escola em especial, as mulheres parecem competir e antipatizar, ironicamente, mais umas com as outras do que com os homens. Durante anos, as mulheres lutaram por igualdade de direitos entre ambos os sexos, mas, quando se depararam com tal equidade, "as outras mulheres", em um "cargo de homem", não gostaram. Como diz dona Helena (ALMEIDA, 1998, p.199): "Mulher não gosta que outra dirija. Ela começa a criar problemas".

É claro que hoje a sociedade já está mais habituada com as mulheres ocupando cargos de poder, cargos políticos, inclusive; mas talvez seja realmente mais cômodo aceitar orientações vindas do sexo masculino, principalmente em se tratando de assuntos que ainda parecem pertencer mais ao universo dos homens, como mecânica de automóveis, por exemplo, ou então em aulas práticas de direção em autoescola, nas quais é perceptível o maior número de instrutores homens, assim como também é maior a procura pelos mesmos. Embora as questões de gênero tenham sido bastante trabalhadas nas últimas décadas, é de suma importância retornarmos a elas quando encontrarmos essa necessidade, pois, enquanto para umas pessoas tudo parece bem esclarecido e resolvido, para outras, infelizmente, ainda existem algumas resistências no que diz respeito à igualdade de sexos, bem como a dificuldade em encarar o fato de que as mulheres invadiram o mercado de trabalho em diversas profissões e não parecem querer abandoná-lo tão depressa.

Por tudo isso - e porque a questão de gênero desperta-nos um desejo de sempre querer discutir mais - fazemos nossas as idéias contidas na obra intitulada Mulher, Gênero e Sociedade, organizada por Andrea Brandão Puppin e Rosie Marie Muraro. O livro está dividido em quatro blocos. O primeiro, Gênero e Cultura, traz à tona conceitos sobre identidade, casamento, família, masculinidade e homossexualidade. O segundo bloco, Mulher e Política, fala sobre a forte presença da mulher no campo político, sua importante participação, e também sobre o assédio sexual muitas vezes sofrido por elas. O terceiro bloco, Mulher, História e Sociedade, vai nos contar da trajetória feminina durante a História, suas conquistas e críticas perante a sociedade, como por exemplo, "sair da cozinha" para trabalhar na indústria, e a importância feminina para a economia. $\mathrm{O}$ quarto e último bloco, Mulher e Literatura, nos fala sobre a força da voz das mulheres na literatura, e o surgimento de uma vertente feminina chamada metaficção historiográfica.

A coletânea é de cunho analítico 
e tem como finalidade analisar o papel da mulher durante a História, em diversos aspectos, sob uma ótica feminista e marxista, na grande maioria dos artigos, trabalhando com a questão de gênero. Pensamos que a escolha deste livro se faz pertinente por explorar assuntos relevantes a quem pretende estudar historicamente tanto a questão da mulher, quanto da sociedade ou de gênero. Essa última palavra, enquanto categoria de análise, pode ser considerada um tema recentemente explorado, pois surgiu no início dos anos 60. A questão foi pensada por mulheres intelectuais, cuja maioria era feminista. Estas, nesse período, começaram a utilizar a palavra "gênero" mais seriamente, num sentido literal; como maneira de se referir à organização social da relação entre os sexos. Assim sendo, estudar as questões de gênero é importantíssimo para entendermos o papel da mulher e do homem no contexto social contemporâneo.

Quando Marx criou a categoria classe social, em meados do século XIX, abriu um campo totalmente desconhecido para a ciência social de seu tempo e acabou por transformar o mundo. Trazendo à luz uma multidão de oprimidos [...] Como os oprimidos, depois de oito mil anos de invisibilidade, as mulheres começam também a exercer um papel cada vez mais determinante nas estruturas políticas, sociais e econômicas. [...] Portanto, a nova categoria gênero, criada pelas mulheres a fim de dar conta do seu papel na História e na condição humana do fim do século $\mathrm{XX}$, vem acrescentar e completar a categoria classe social, para dar conta da existência da opressão de diversas naturezas postas na História (MURARO, 2001, p.7-9).

A nova categoria "gênero", conforme Muraro, passou a ser usada primeiramente para mostrar a discriminação sofrida pelas mulheres em diversos níveis, como por exemplo, o econômico, o social e o político,

[...] depois, passou-se a elaborar uma epistemologia questionando as bases da filosofia platônica e cartesiana, baseada na objetividade, na abstração e nas generalizações [...]. Neste último início de século e de milênio desmorona o dualismo platônico mente/corpo, razão/emoção que foi a base de todo pensamento ocidental nesses últimos três mil anos, e que serviu apenas como racionalização do exercício do poder expresso nas relações senhor/ escravo, homem/mulher, opressor/ oprimido, etc. Esta nova maneira de elaborar abre uma nova forma de pensar pós-cartesiana e pós-patriarcal (MURARO, 2001, p. 7- 8).

Para essa autora, a idéia da "generalização" é bastante delicada, pois a sociedade deixa de ser vista como "partes complexas", que merecem mais empenho nas análises, e passa a ser tratada como um "todo homogêneo". Ora, nós sabemos que isso não funciona muito bem, afinal, os problemas não são os mesmos em todos os lugares e, mesmo que sejam, as formas de tratá-los não o são, porque os sujeitos são singulares, cada um agirá a partir da sua perspectiva de vida, de cultura, de conhecimento, dentro do momento histórico em que esteja inserido. Sabemos das inúmeras dificuldades atravessadas ao longo da história, e ainda nos dias atuais, pelas mulheres para alcançar o reconhecimento merecido, principalmente no campo profissional. Não é novidade ver uma mulher exercer a mesma função de um homem em uma empresa, mas receber menor salário.

$\mathrm{Na}$ maioria dos artigos contidos na coletânea mencionada acima, esse problema é criado ainda na infância, quando os meninos ganham carrinhos, e as meninas bonecas e panelas. Essa diferença, que se inicia com as brincadeiras de meninos e meninas, tem perpassado inúmeras gerações. Conforme 
referimos anteriormente, quem já não ouviu que "tal função" é de homem, e "tal função", como por exemplo, cuidar dos filhos e da casa, é coisa de mulher? A questão é que, com o passar do tempo, as mulheres foram deixando as diferenças de lado e invadindo o dito universo masculino, disputando lugar no mercado de trabalho, no campo político e recebendo destaque social.

Desde Weber, o antagonismo de valores presente no mundo social nos impede de elaborar pressuposições que definitivamente atribuam posições, lugares e/ou papéis definitivos para o ser humano. Essa posição é ainda mais evidente e contundente para a dimensão relacional de gênero onde várias dinâmicas estão atuando e promovendo um fluxo intenso de transformações e mudanças (ALMEIDA, 2001, p. 29).

Ou seja, o mundo masculino foi entrando em crise. Segundo Soihet (2001, p. 99), "o comportamento feminino reivindicador de uma participação mais plena na sociedade é visto como uma ameaça à ordem constituída sob o signo dos interesses masculinos [...]". E sabemos que, durante o século XIX, a medicina assegurava, com respaldo científico, a inferioridade feminina, devido às nossas condições biológicas, como a "fragilidade" física e afetiva, e a vocação maternal. Vejamos da seguinte forma: se, de fato, a mulher estivesse errada em desamarrar os laços familiares, por exemplo, deixando de ficar em casa, cozinhando, passando e educando os filhos, a parte econômica da sociedade não deveria precisar dela tanto quanto precisa, pois só no Brasil, de acordo com Melo (2001, p. 124), "a taxa de participação feminina no mercado de trabalho cresceu cerca de 13 pontos percentuais entre 1950 e 1980 , chegando nos anos 90 a beirar os $40 \%$ [...] e tudo indica que continuará crescendo nos próximos anos".
Tendo a mulher sofrido, e contemporaneamente continuar sofrendo, com problemas na ordem das relações sexuais, tais como assédios, muitas vezes ocorridos no campo profissional, ou como infecções por doenças sexualmente transmissíveis, como a Aids, pelo próprio marido ; chegou o momento de ela se fazer ouvir e extinguir definitivamente as diferenças entre homens e mulheres.

Assim como a sociedade despertou diante da descoberta de Marx sobre classes sociais, também deve despertar para a descoberta das mulheres na História. Claro que já estávamos inseridas nas classes sociais, afinal, sempre pertencemos à sociedade, mas não estávamos sendo vistas da forma como devemos ser vistas. Conforme sabemos, em algumas civilizações antigas, as mulheres eram mais importantes que os homens, justamente por poderem gerar filhos, "qualidade" que hoje ainda é levada em conta na hora de empregar mulheres (em alguns setores), devido à temida licença maternidade que, em alguns lugares, aumentou de quatro para seis meses.

No que diz respeito ao tema aqui desenvolvido, sabemos das mudanças de comportamento da sociedade ao longo dos tempos, inclusive em relação ao magistério, o qual, em seus primórdios, foi tido como ofício somente masculino, passando posteriormente a ser trabalho para mulheres, e hoje se tornando uma profissão tanto de mulheres, quanto de homens, que optam por diferentes disciplinas, pelo sonho da realização profissional.

Quanto ao ensino e ao modo de ensinar como um todo, também houve várias mudanças, mas nem todas para melhor. É necessário que tanto professores como professoras atualizem-se, e, mais que isso, é necessário também que nos inspiremos em nossos bons professores e formemos, de fato, uma nova geração de docentes, geração esta preocupada com a escola, com a família, 
ENSINAR, UMA PROFISSÃO FEMININA? EXPLANANDO ASPECTOS CONCEITUAIS E

com a aprendizagem, com a comunidade, enfim, com o mundo em que vivemos, independente de nossa condição de gênero.

\section{Referências bibliográficas}

ALMEIDA, Marlise M. de Matos. Masculinidade: uma discussão conceitual preliminar. In.: MURARO, Rosie Marie; PUPPIN, Andrea Brandão (Orgs). Mulher, Gênero e Sociedade. Rio de Janeiro: Relume Dumará; FAPERJ, 2001, p. 21-28.

ALMEIDA, Jane Soares de. Mulher e educação: a paixão pelo possível. São Paulo: Editora UNESP, 1998. (Prismas)

LOURO, Guacira Lopes. Gênero, História e Educação: construção e desconstrução. In.: Educação e Realidade. Porto Alegre. v. 20 n. 2, jul/dez 1995. UFRGS/RS.

Gênero, sexualidade e educação: Uma perspectiva pós-estruturalista. 4. ed. Petrópolis, RJ: Vozes, 2001.

MURARO, Rosie Marie; PUPPIN, Andrea Brandão (Orgs). Mulher, Gênero e Sociedade. Rio de Janeiro: Relume Dumará; FAPERJ, 2001.

SOIHET, Rachel. Sutileza, ironia e zombaria: instrumentos no descrédito das lutas das mulheres pela emancipação. In.: MURARO, Rosie Marie; PUPPIN, Andrea Brandão (Orgs). Mulher, Gênero e Sociedade. Rio de Janeiro: Relume Dumará; FAPERJ, 2001, p. 99111.

WERLE, Flávia. Práticas de Gestão e Feminização do Magistério. In: Cadernos de Pesquisa. São Paulo. V. $35, \mathrm{n}^{\circ}$ 126, set/dez 2005, p. 609-634. 